Classification

Physics Abstracts

$61.16 \mathrm{D}-61.16 \mathrm{~F}-07.80$

\title{
In situ experiments in the new transmission electron microscopes
}

\author{
J. Pelissier and P. Debrenne
}

CEA-CEREM, Centre d'Etudes Nucléaires de Grenoble, BP 85X, 38041 Grenoble Cedex, France

(Received January 18, 1993; accepted February 26, 1993)

\begin{abstract}
Résumé. - La sensibilisation des constructeurs de microscopes électroniques à transmission aux performances de très haute résolution les conduit à concevoir des espaces objet difficilement compatibles avec la possibilité de recevoir des porte-objets instrumentés plus ou moins complexes. Cela implique quelques adaptations particulières à mettre en oeuvre en concertation avec le constructeur. Nous présentons les concepts de développement de l'expérimentation in situ applicables aux microscopes à transmission modernes de tension moyenne. Les difficultés et les écueils à éviter sont illustrés au moyen d'un exemple de réalisation complexe de porte-objet: "un porte-objet de traction chauffant à double inclinaison". Nous comparons les possibilités offertes par les constructeurs JEOL et HITA$\mathrm{CHI}$ pour cet exemple de réalisation.
\end{abstract}

\begin{abstract}
The sensibilization of microscope builders to the interest of very high resolution lead them to design transmission electron microscopes with specific specimen chambers, which do not fit complex specimen holders as usually used for in situ experiments. They need therefore some particular adaptations to set up in concertation with manufacturers. We present here some concepts of development of in situ experimentation adaptable to modern transmission electron microscope operating at intermediate voltage (200-400 kV). The difficulties and dangers to be avoided are illustrated on an example of design of a complex specimen holder: "a side-entry stage with straining, heating and double-tilt facilities". We compare the possibilities offered by two manufacturers, HITACHI and JEOL, for this particular realization.
\end{abstract}

\section{Introduction.}

Microscope manufacturers and research laboratories have shown during many years of evolution of the technique that High Voltage Electron Microscopy yields significant improvements in the three following points:

- appreciable increase of resolution

- investigation of specific electron- matter interactions due to the high energy of electrons

- in situ experiments on thicker specimens due both to a higher penetration of electrons and to the available volume in the specimen chamber.

Concerning the increase in resolution, the best lattice resolution limits reached by HVEM $(0.15 \mathrm{~nm})$ are also nearly reached at intermediate voltages $(0.17 \mathrm{~nm}$ at 300 or $400 \mathrm{kV})$ due to the improvements of electron optics. Experiments on electron-matter interactions are specific 
of basic research, whereas in situ experiments are more dedicated to applied research on industrial materials, in particular in metallurgy. Except some particular cases, as for instance studies of mechanical properties under electron irradiation of materials for nuclear industry, where high voltages are compulsory, in situ experiments can be performed on more conventional microscopes.

\section{Choice criteria of the microscope.}

The thickness of foils for in situ experiments must be large enough to make the experiment representative of the bulk material (surface effects, characteristic size of observed features, ...). It is then necessary to increase electron penetration by the means of a high acceleration voltage, while keeping radiation damage whithin reasonable limits. Penetration significantly increases between 0 and $400 \mathrm{kV}$, but the increase rate slows down at higher voltages, and most common metals have a threshold for radiation damage between 300 and $500 \mathrm{keV}$. This voltage range is then the best compromise.

In situ experiments often need complex specimen holders, which are most conveniently designed in a "side entry" version. The pole piece gap of the objective lens has to be large enough to allow confortable translation and tilting facilities.

Then resolution depends both on the electron wavelength and on the pole piece gap through the spherical aberration coefficient.

The 300 and $400 \mathrm{kV}$ microscopes seem to give the best compromise between penetration, radiation damage and resolution. However, in this range of accelerating voltage, manufacturers propose microscopes with very small specimen chambers, which do not allow the introduction of complicated stages. A combined design of these stages and of the specimen chambers is then necessary.

\section{Difficulties in the design of complicated specimen holders.}

We shall discuss here the difficulties encountered in the design of a side-entry stage with straining, heating and double-tilting facilities on a concrete example. The principle is shown in figure 1 . The load (up to $1500 \mathrm{~g}$ ) is applied to the sample through a tungsten wire (diameter $0.15 \mathrm{~mm}$ ) which allows double tilting $\left(\alpha_{1}= \pm 40^{\circ} ; \alpha_{2}= \pm 8^{\circ}\right)$. The maximum temperature in operation is $1100 \mathrm{~K}$. An electronic regulation ensures a constant load during changes of temperature and tilt $\left(\alpha_{2}\right)$. Figure 2 shows part of a tensile-heating stage we have designed and which is adaptable to JEOL $200 \mathrm{CX}$ and $2000 \mathrm{FX}$ microscopes.

3.1 SIZE LIMITATION OF THE HOLDER DUE TO THE GONIOMETER. - The various controls necessary to operate the holder must travel through the goniometer, inside the cylindrical part of the stage. Two examples are shown in figure 3. The diameters of the cylindrical part of the stage given by the manufacturers are:

$\begin{array}{lll}\text { JEOL } & 200 \mathrm{CX}-2000 \mathrm{FX} & 13.7 \mathrm{~mm} \\ & 2010-3010 & 16 \mathrm{~mm} \\ & 4000 \text { series } & 13.8 \mathrm{~mm} \\ & & \\ \text { HITACHI } & \text { H } 9000 \text { NAR }(300 \mathrm{kV}) & 13.5 \mathrm{~mm}\end{array}$




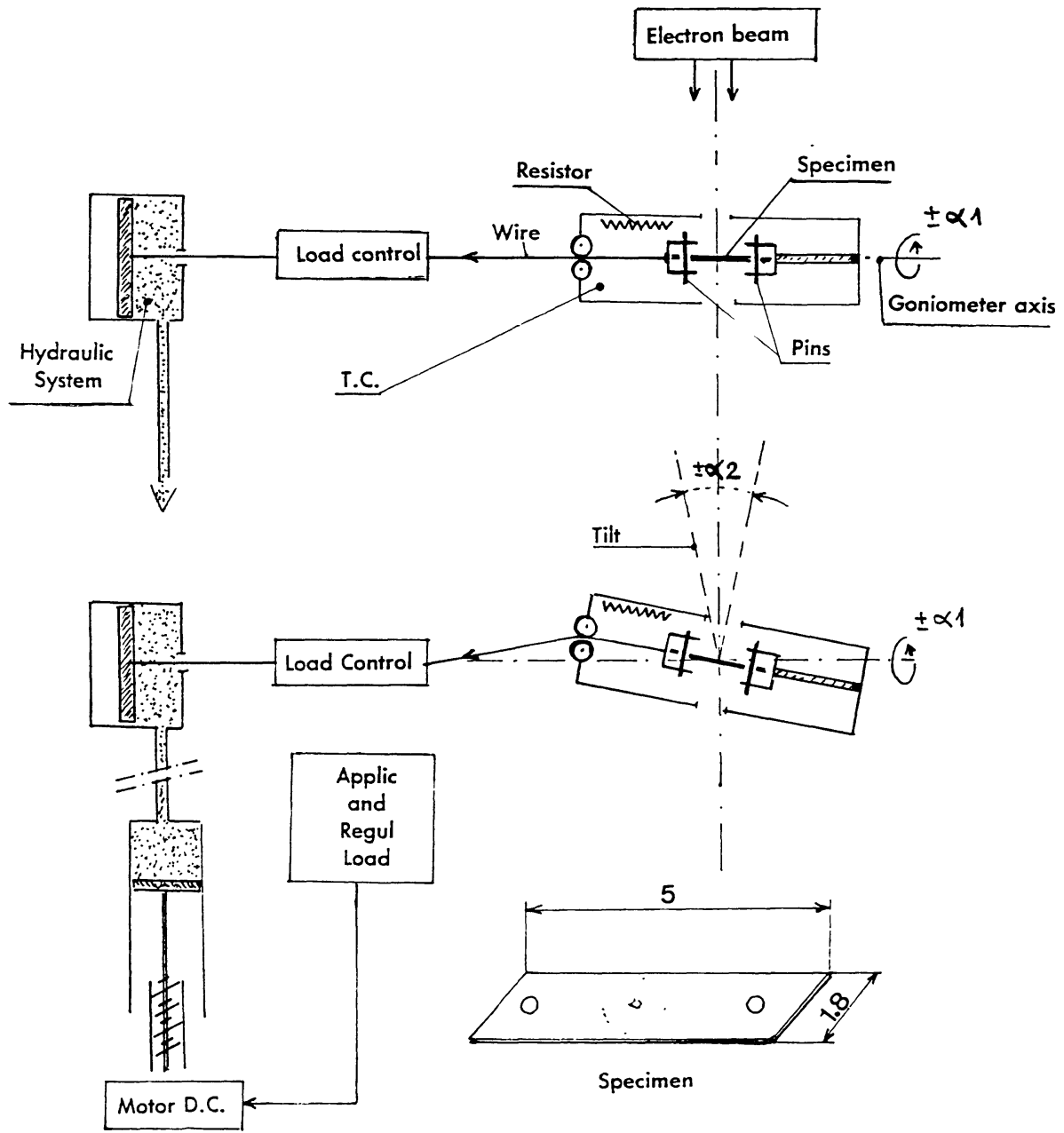

Fig. 1. - Schematic diagram of a side entry stage with straining, heating and double tilting facilities.

3.2 Limitations DUE TO THE GAP OF THE ObJECTIVE POLE PIECE. - The gap of the objective pole pieces is usually about 4 to $6 \mathrm{~mm}$. The dimensions of the part of a complex stage located inside the pole pieces can be $5 \times 9 \times 25 \mathrm{~mm}$. It is then necessary to design pole pieces whose characteristics are given in figure 4.

3.3 OBJECTIVE APERTURE POSITION AND ANTICONTAMINATION DEVICE. - The increase of the gap and the size of the specimen holder lead to a modification of the position $z$ of the objective aperture and of the shape of the anticontamination device.

3.4 VACUUM GATE POSITION INSIDE THE GONIOMETER. - The new standard stages are very short: the distance between the axis of the sample and the tip of the specimen holder is about $8 \mathrm{~mm}$. During the introduction of the stage into the microscope, this tip comes very close to the vacuum gate of the goniometer. The length of in situ holders might be larger, and in this case 


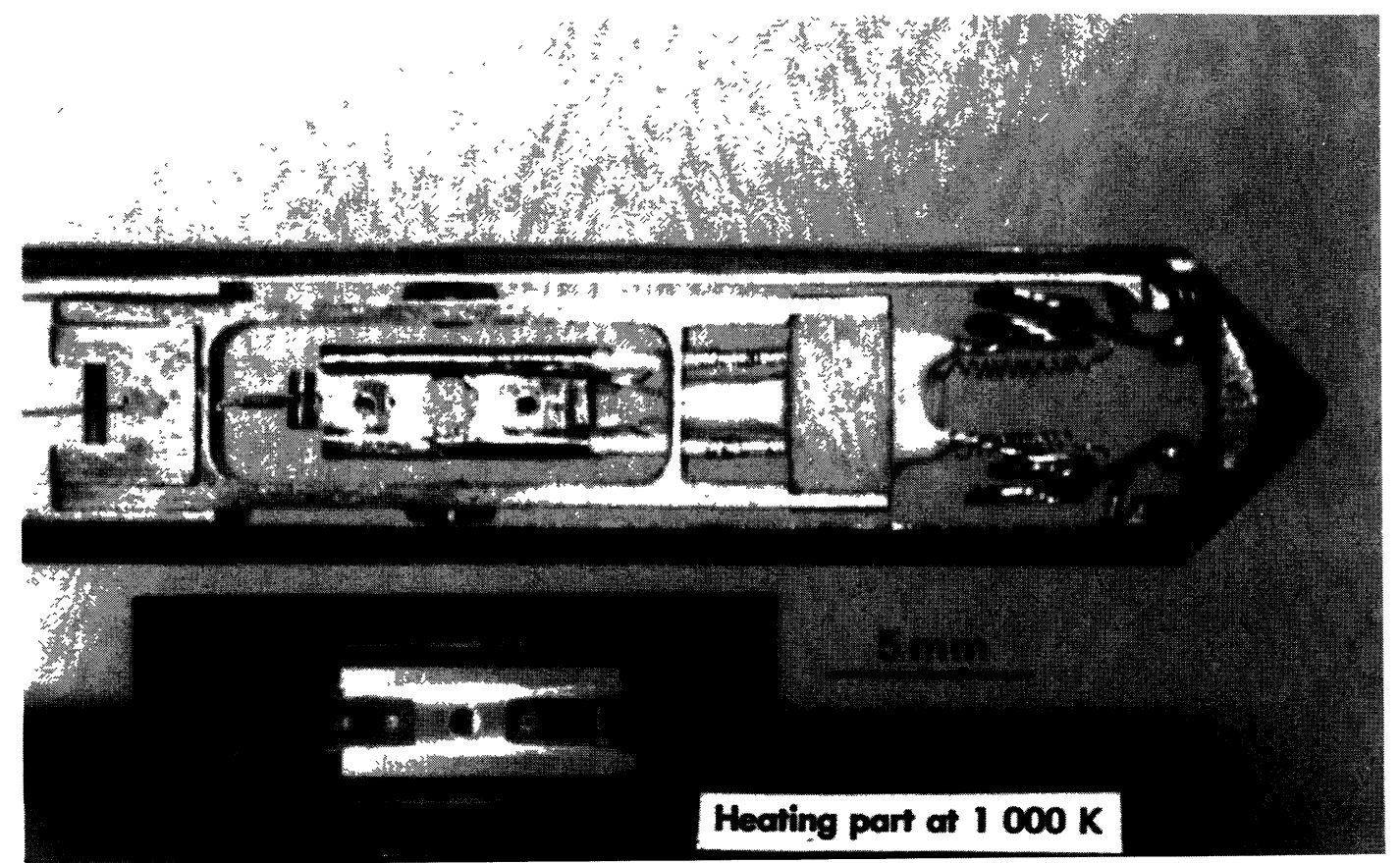

Fig. 2. - Detail of the stage shown in figure 1: note the homogeneity of temperature of the specimen at the center of the microfurnace.

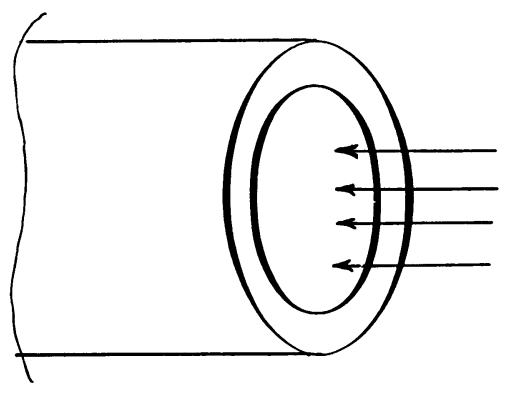

\section{For a straining stage with heating and tilting capabilities}

\section{Control of temperature}

Heating power supply

Drive second tilt

Load application

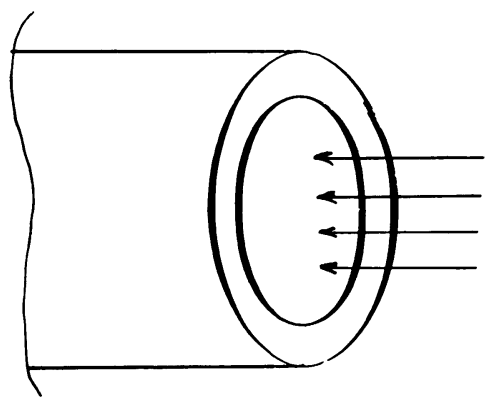

For deformation holder with liquid Helium cooling

Regulation temperature and control

Cooling device

Thermal screens

Load application

Fig. 3. - The diameter of the cylindrical part of the stage must be large enough to allow different controls to reach the specimen region (see text). 


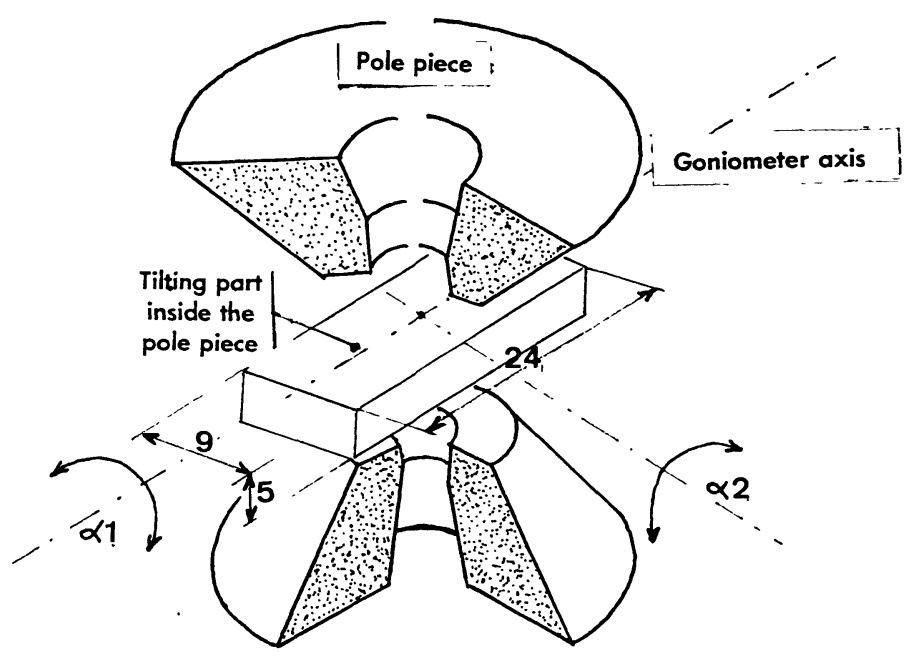

\section{POSSIBILITIES}

JEOL

JEOL $200 C X$ : standard pole piece JEOL 3010 : special symetric pole piece

\section{Specifications :}

Gap : $10 \mathrm{~mm}$

$C_{s}=0.25-C_{e}=2.75-F=3.48$

Resolution $=0.25 \mathrm{~nm}$ point to point

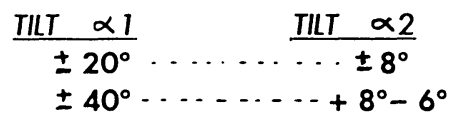

HITACHI

Hitachi 9000 NAR : special assymetric pole piece

Specifications :

Gap : $13.5 \mathrm{~mm}$

Resolution $=0.3 \mathrm{~nm}$ point to point

$\frac{\text { IILT } \alpha 1}{ \pm 40^{\circ}} \ldots \ldots \frac{\text { TILT } \alpha 2}{ \pm 8^{\circ}}$

Fig. 4. - Designs of the objective pole pieces.

the cyclindrical part of the stage should be fitted with a device allowing the holder to stand back during primary pumping and then to be moved forward to the right position, with the sample on the beam axis. This device shown in figure 5 has been designed for the goniometers of the JEOL 2010 and 3010 microscopes and can be adapted to the HITACHI 9000 NAR.

3.5 $X$-TRANSLATION OF THE SPECIMEN HOLDER - In the new JEOL microscopes, this control is comprised in the goniometer itself (Fig. 6), instead of being operated through a rod pushing the holder tip. This new technology suppresses thermal losses at the contact point between the rod and the holder tip. This is quite important for low temperature stages.

\section{Conclusion.}

It is difficult for microscope manufacturers to commercialize a complete set of stages ranging 

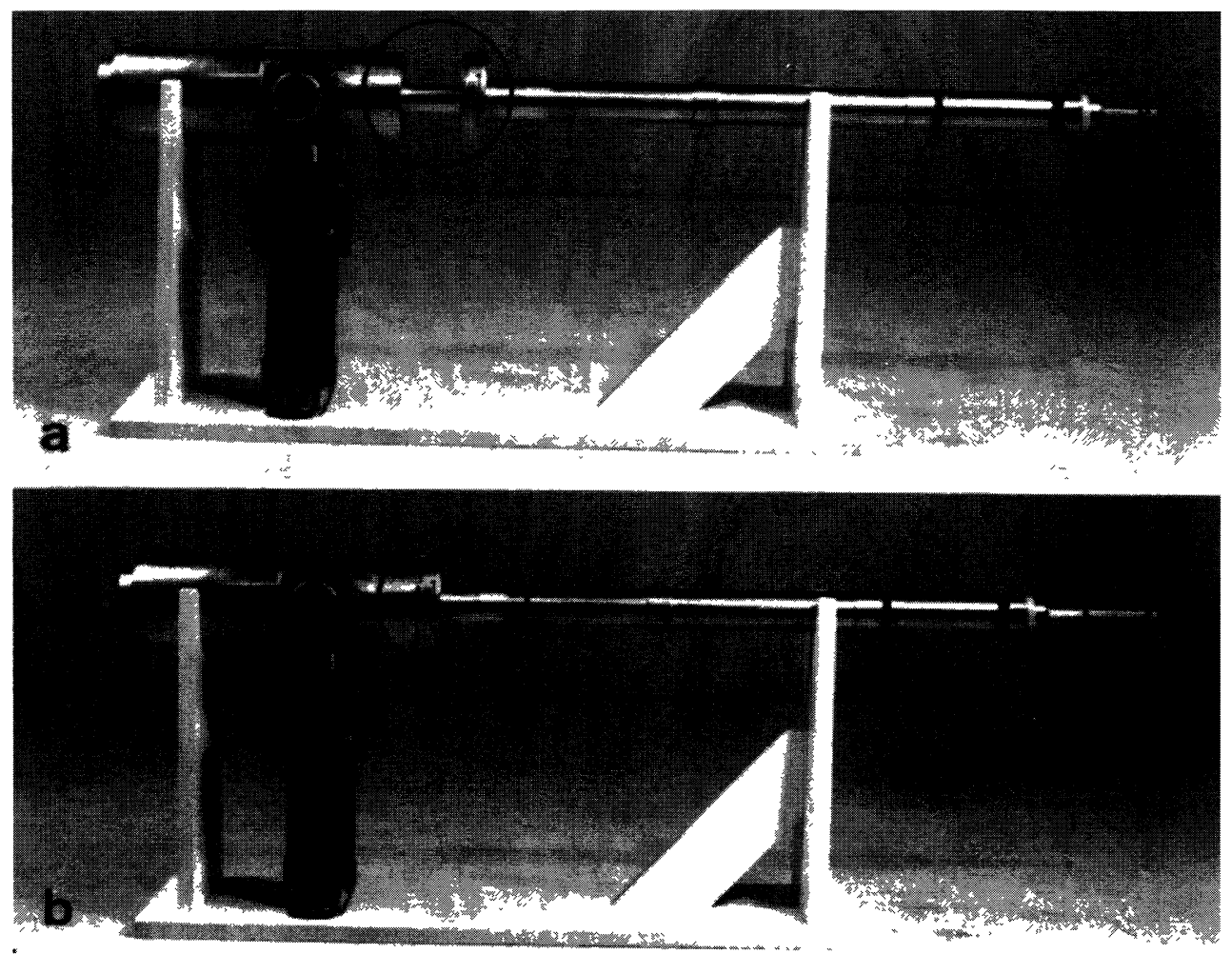

Fig. 5. - Special device for the introduction of a long specimen holder into 2010 and 3010 JEOL microscopes. a) special position for primary pumping inside the goniometer. b) normal position inside the microscope column.

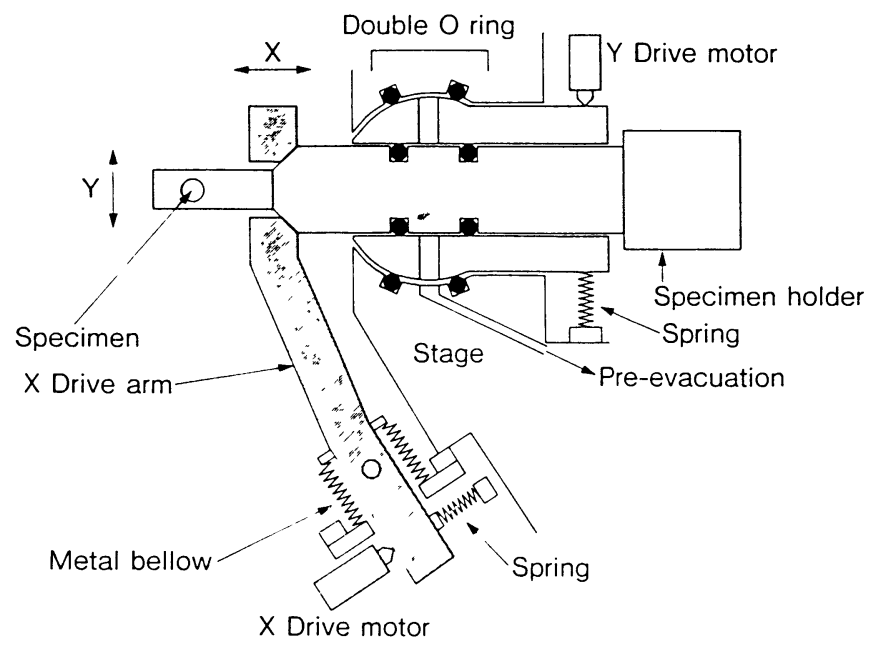

Fig. 6. - New goniometer for 2010 and 3010 JEOL microscopes (from JEOL documents). 
from the simplest to the most complex ones. The goal of the present paper is not to discuss the advantages and drawbacks of HITACHI and JEOL microscopes. The two series of machines has considerable advantages and each of the corresponding manufacturers is prepared to design the compulsory modifications and adjustments discussed above. We tried to show that, though modern transmission microscopes are optimized for analysis and high resolution imaging, the design by research laboratories of specific and complex stages for in situ experimentation is possible. 